\title{
水利建筑工程中的碾压混凝土坝施工与管理分析
}

\author{
王钊 \\ 陕西省土地工程建设集团有限责任公司 \\ DOI:10.32629/hwr.v4i8.3231
}

\begin{abstract}
[摘 要] 国内水利水电工程在新时代的发展进入了新的阶段。近年来, 碾压混凝土坝施工技术作为一种 新兴发展起来的筑坝技术, 凭借其施工高效、造价低廉等优点,被广泛应用在了水利工程当中。碾压混凝 土坝施工质量现场控制一直是较为重要的技术问题,为了满足碾压混凝土坝施工质量管理要求,基于此, 本文阐述了水利工程中的碾压混凝土坝施工材料准备, 对水利工程中的碾压混凝土坝施工要点及其施 工管理进行了论述分析。
\end{abstract}

[关键词] 水利工程; 碾压混凝土坝; 施工材料; 施工要点; 施工管理 中图分类号：TV731 文献标识码：A

\section{1 碾压混凝土坝的概述}

碾压混凝土坝是用振动碾分层碾压 干硬性混凝土筑成的坝, 与常态混凝土 坝相比, 其具有以下主要特征: 第一、采 用坉落度接近于零的超干硬性混凝土修 筑坝的主体。第二、采用自卸汽车、皮 带输送机、真空溜槽或管道运送熟料上 坝。第三、浇筑时不分纵缝, 有的用振动 切缝机造横缝, 有的采用预制混凝土模 板等贯通成缝或间断成诱导缝, 有的甚 至不设横缝而全断面通仓浇筑。第四、 用推土机平仓, 振动碾压实等。第五、温 控措施简化。

\section{2 水利工程中的碾压混凝土坝} 施工材料的准备分析

水利工程中的碾压混凝土坝施工材 料准备主要表现为:

\section{1 原材料准备}

碾压混凝土坝所需的原材料几乎与 一般的水泥混凝土一样, 就是水泥、粗骨 料、细骨料和掺合料等, 然后将这些原材 料和水按照一定的比例进行配置。碾压 混凝土坝中所需的掺合料有硅灰、粉煤 灰和磨细的矿渣以及适量的外加剂等 等。其中硅灰的作用是促凝, 适用于坝面 或者具有较强腐蚀性的结构中。矿渣的 作用是自身硬化可以加强碾压混凝土坝 的干硬性。外加剂主要是指减水剂、缓 凝剂、早强剂和阻锈剂等, 这些外加剂在
拌入料之前需要对水泥、外加剂和掺合 料之间做相容性实验, 只有相容才能进 行拌制。

2. 2 混凝土配合比设计的技术要点 分析

混凝土配合比的设计方法是绝对体 积法, 在设计时主要需要确保抗渗性、强 度、抗冻性等这些因素符合大坝的实际 要求, 碾压混凝土坝的材料组成与混凝 土质量更是息息相关, 因而要对这些材 料和各种指标进行严格要求。关于原材 料的指标主要有: 含水率、级配、表观 密度、粒径、外加剂性质、外加剂种类 和其相容性等。

3 水利建筑工程中的碾压混凝 土坝施工与管理分析

\section{1 材料含量}

沙石粉是一种粒径在 0.16 毫米以 下的颗粒, 是粗骨料生产中一种重要的 成分, 在碾压混凝土的生产中需要控制 好沙石粉的含量, 其含量不得超过总量 的 $18 \%$ 同时也不可以低于 $16 \%$ 。混凝土施 工要满足抗裂性, 要满足抗裂性混凝土 中沙石粉的含量要控制在 $10 \% \sim 14 \%$, 但 是这种处理方式与沙石粉生产环节的 要求背道而驰, 这样的方式会导致施工 质量受到一定的影响, 所以材料选择可 以考虑使用粉煤灰, 替代原本的沙石粉, 这样就可以达到配比的要求也满足抗
裂性能。

3. 2 拌制混凝土的方法

对于混凝土的搅拌我们要根据施工 要求进行, 这样是为了最大限度的确定 施工材料的使用数量。施工材料一定要 符合国家标准, 同时要对其进行细致周 密的检查, 然后将其按照一定得比例进 行严格配比, 搅拌时要以材料均匀性为 前提, 在需要借助机械设备的时候, 我们 就需要借助机械设备, 强制搅拌机是比 较常见的, 它的应用大多数情况下, 是为 了避免混凝土在搅拌时出现离析的现象, 混凝土的搅拌时间会受很多因素的影响, 其中包括: 运输长短, 试验结果等等。

3. 3控制好施工环境的温度变化, 防 止混凝土出现开裂的情况

在施工的过程中, 碾压混凝土使用 的胶凝材料较少, 并且能够用粉煤灰代 替部分水泥, 降低水化热程度, 但是由 于实际施工中, 碾压混凝土坝体不会设 置冷却水管, 因此为了避免混凝土内部 温度和环境温度的差异性, 需要对碾压 混凝土施工的温度进行严格控制, 避免 因为温差过大而出现开裂现象。为了避 免这一问题, 要充分利用碾压混凝土特 有的性质特征, 尽量的缩短混凝土的运 输路程, 确保及时碾压。由于在浇筑碾 压混凝土的时候因为其松散的状态会 使得其颗粒之间充满了流动的空气, 加 
快其与外界的热量交换, 因此一定要尽 量的减少其层面在空气中的暴露时间, 这样能够有效的避免因为温差的原因 而出现裂缝。

3. 4 入仓浇筑施工分析

主要体现在: (1) 自卸汽车入仓。为 了保障混凝土入仓的操作性, 在本项目 中, 高程在 $120 \mathrm{~m}$ 以下的混凝土浇筑全部 采用自卸汽车入仓的方式, 在入仓前, 为 保持浇筑面清洁, 避免杂质干扰, 必须对 汽车轮胎与车面进行冲压水枪清洗, 清 洗后, 要设置 $100 \mathrm{~m}$ 的脱水路段, 并设置路 表排水沟, 以避免污水进入浇筑仓内。(2) 负压溜槽入仓。对于高程在 $120 \mathrm{~m}$ 以上的 区域, 受场地条件限制, 无法使用自卸汽 车运输入仓, 因此要使用负压溜槽入仓 的方式, 在大坝坝肩左侧区域设置三条 负压溜槽, 每条溜槽断面面积为 $1.5 \mathrm{~m}^{2}$, 为保证仓内安全以及仓内混凝土温度, 仓内落料最大垂直高度为 $30 \mathrm{~m}$, 并在出料 口采取抗分离装置, 以保证浇筑混凝土 的整体性。

3.5 对混凝土大坝裂缝的处理技术

即使在混凝土施工技术之后, 也不 可避免的出现一些瑕疪, 裂缝就是比较 严重的问题之一, 因此需要采取专业的 手段对裂缝进行处理。在大坝的上游, 要采用比较严格的温度保护措施, 比如 可以在大坝上游部分的混凝土地段进行 加保温板处理, 避免裂缝的产生, 这是一 项最基本的措施。另外, 在大坝内如果有 多余的水分, 就应该防止坝内外的温差 过高而产生混凝土裂缝问题, 同时还要 防止大坝内的水对坝体产生过高的压 力。当大坝进行蓄水之前, 要检验水压是 否会渗入到大坝内部, 如果发现可能会
有此问题产生, 一定要提前采取措施, 如 果是大坝注水之后才发现这样的问题, 可以在裂缝上建排水通道, 降低大坝内 的水对混凝土裂缝产生过高的压力, 及 时的采取防护措施, 确保混凝土裂缝对 大坝的负面影响最低。

\section{6 碾压混凝土的运输}

碾压混凝土的运输可使用皮带输送 机、自卸汽车、真空溜槽和吊罐等运输 机具; 但不能使用常规溜槽来直接进行 碾压混凝土的运输。

(1) 自卸汽车在入仓前要把轮胎清 洗干净, 避免将泥土、脏水等物质带到 仓内; 运输机具在使用之前必须要进行 全方位的清洗和检查。使用自卸汽车来 进行碾压混凝土的运输时, 必须保证自 卸汽车能够在平整的道路上行驶, 且要 一次运达仓面, 中途严谨停歇; 汽车在 仓面行驶时应保持匀速状态, 不能进行 急刹车、急转弯等操作, 否则会对混凝 土的质量造成损伤; 在高温的季节施工 时, 需要对温控混凝土运输车进行遮阳 和防晒。

(2) 使用皮带输送机进行碾压混凝 土的运输时, 不能直接将混凝土带到仓 内, 且应将具有遮阳保温、防雨防潮的盖 棚搭设在皮带机上, 从而防止水分的蒸 发; 在卸料处需设置挡板和刮板, 防止出 现骨料分离或砂浆损失的状况。

（3）使用吊罐进行碾压混凝土的运 输时, 需要采取一定的防分离措施。当同 时进行有两种以上标号碾压混凝土的运 输时, 需要在运输设备上设置不同的标 志来对混凝土加以区分。在运输灰浆时, 为了保证浆液运送到現场时能保持均匀, 应对浆液采取一定的防沉淀措施。

\section{7 事后质量控制}

事后质量控制主要指通过对养护到 龄期后的实体质量进行检测, 判定实体 质量是否达到设计指标要求。水利枢纽 工程碾压混凝土实体质量检测指标包括 透水率、抗压强度、抗渗等级。目前, 工程已对到一定高程的碾压混凝土质量 进行了检测, 检测的坝段有 5, 6, 20,21坝 段, 共检测17孔, 26段/次。试验孔的区域 包括上游 $50 \mathrm{~cm}$ 变态混凝土区域、上游 $2 \mathrm{~m}$ 防渗区域及内部。局部试验段压水试验 未满足要求, 主要出现在坝体内部。通过 对未满足要求的区域灌浆, 处理后的区 域压水试验透水率能够满足要求。芯样 的抗压强度与抗渗等级可满足设计指标, 说明碾压混凝土配合比方案是可行的。 通过压水试验检测, 上游 $50 \mathrm{~cm}$ 变态混凝 土区域未出现质量问题。

\section{4 结语}

总而言之, 基于碾压混凝土坝的层 面及缝面渗流特点, 需要结合工程实际 情况, 做好坝体施工质量现场控制工作, 关注层面和缝面施工质量, 采取合理的 碾压混凝土坝施工质量现场检测方法, 加强施工细节管理, 保证碾压混凝土施 工质量安全。

\section{[参考文献]}

[1]姜晓辉,何君.水利施工中碾压混 凝土施工的技术要点浅析 [J].中国标准 化,2017,(08):156-157.

[2]杨军.碾压混凝土大坝施工 在水利工程中的运用 [J]. 四川建 材,2017,43(07):111+113.

[3]黄巍.碾压混凝土施工 $[M]$. 北京: 中国水利水电出版社,2015. 